تقييم دور العلاقات العامة في الجامعات الليبية الخاصة

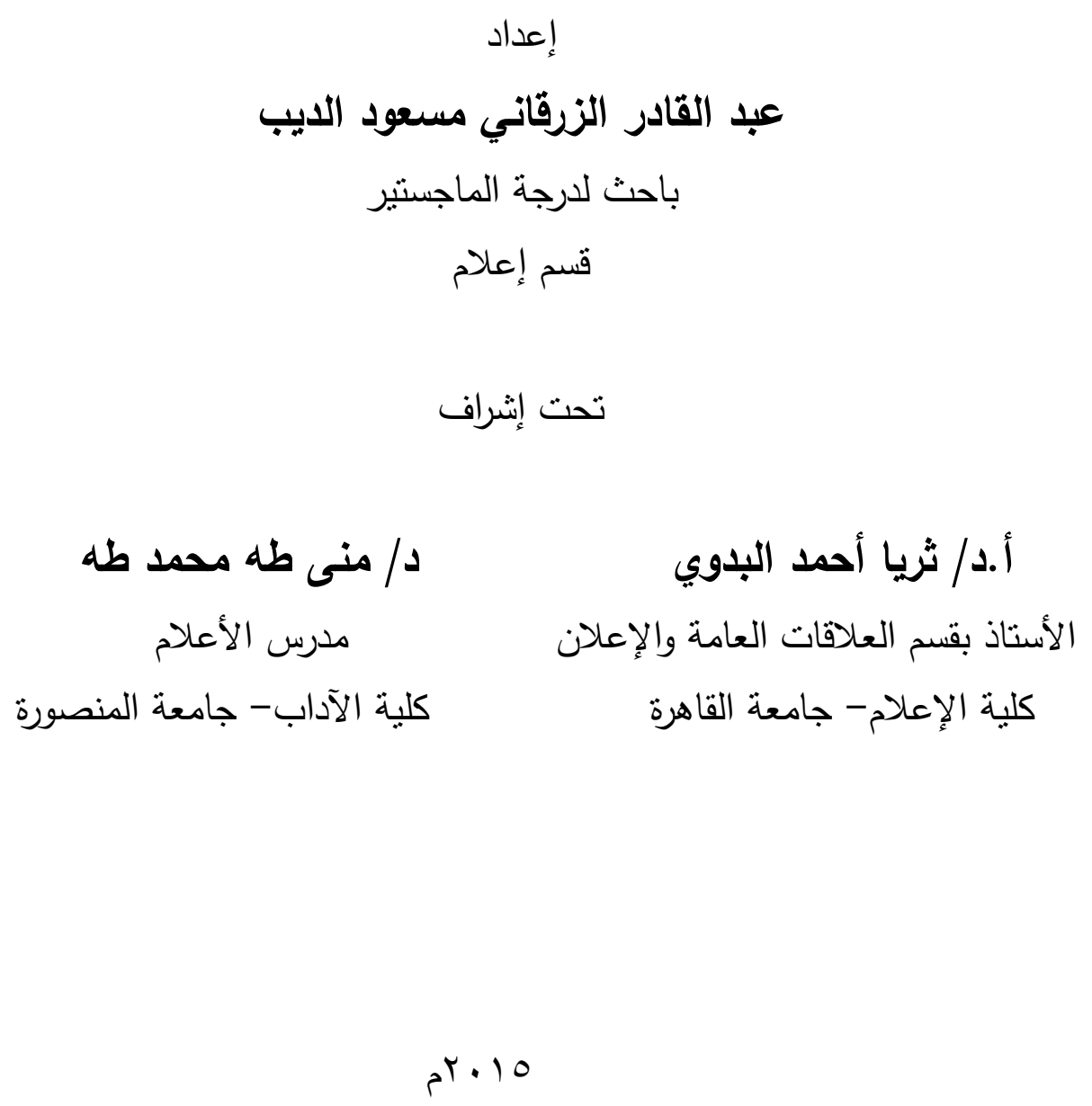




\section{تقييم دور العلاقات العامة في الجامعات الليبية الخاصة}

عبد القادر الزرقاني مسعود الديب

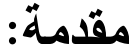

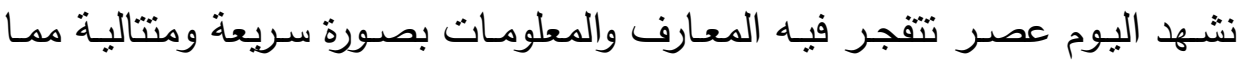

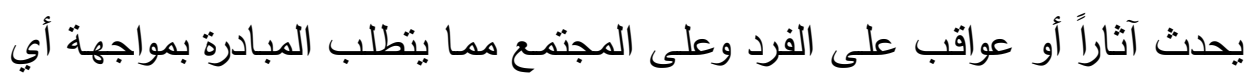
عواقب قد تكون وخيمة ، إن ما يحدثه العلم والتكنولوجيا ليس قاصرا على المجال

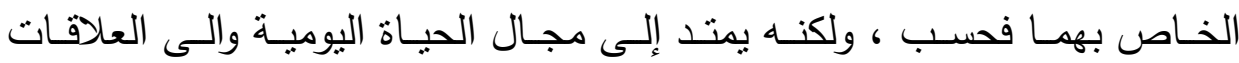

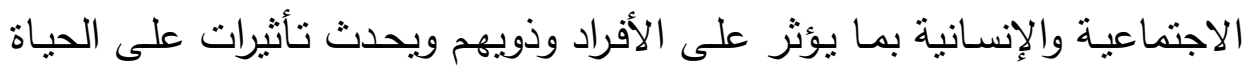

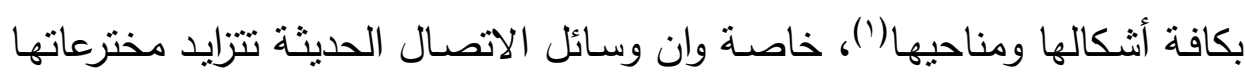

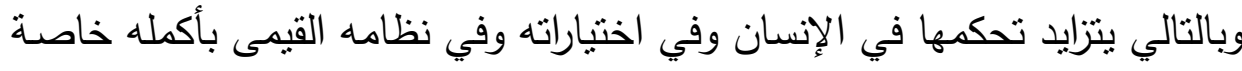
بعد الطفرة الهائلة التي شهدتها صناعات الاتصال وما ترتب عليها من نتائج(؟).

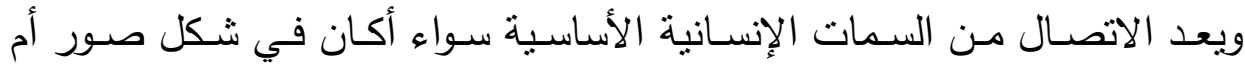

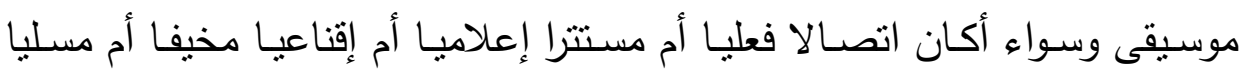

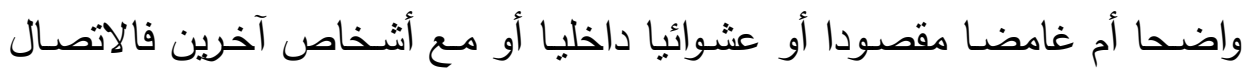

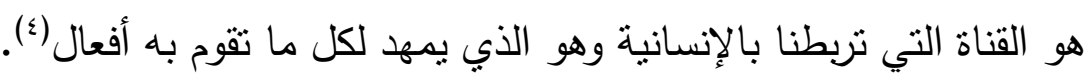

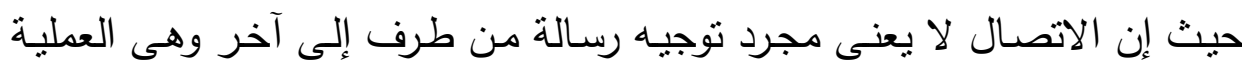

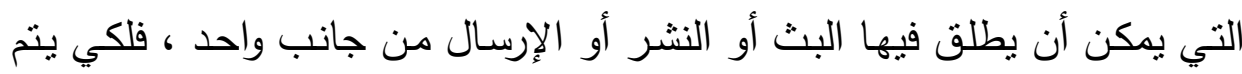

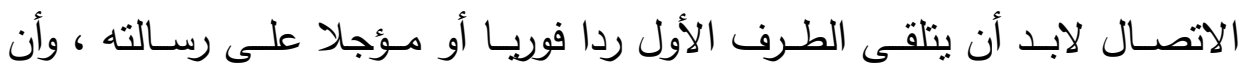
تستمر الردود مع استمرار توجيه الرسائل .

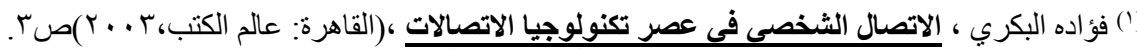

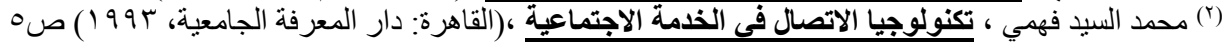
(ङ) Bittner. R.J Mass Communication. An Introduction. 4. ed .N.Y:PrenticeHall.Inc.1986.P.8. 


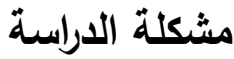

تلعب العلاقات العامـة دوراً هامـاً ضمن السياق التتظيمي للمؤسسات بشكل عام

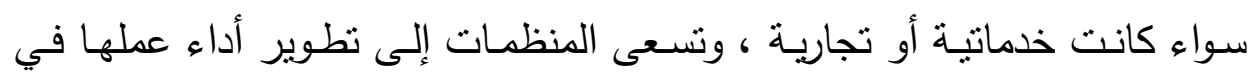
سياق النطورات التي تصاحب عملها على الصعيد الداخلي للمؤسسة أو خارجها

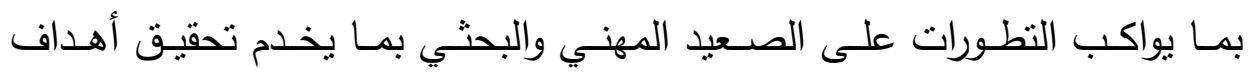

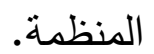

وضمن سياق هذا التطور شهدت الدولة الليبية تتوعا كبيرا في ظهور المؤسسات

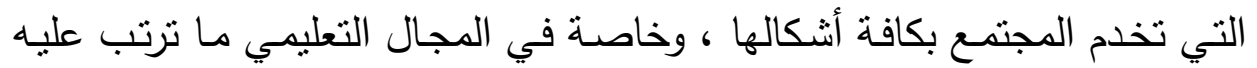
ظهور الجامعات الخاصة في مطلع القرن الحادي والعشرين. غير أن هذا التطور

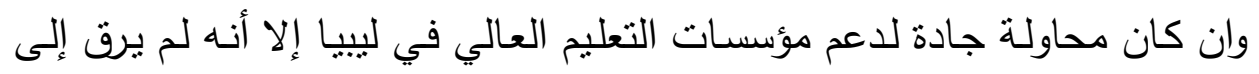

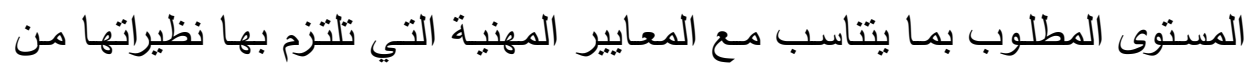

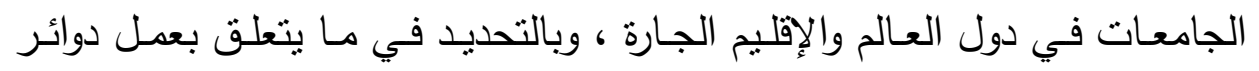

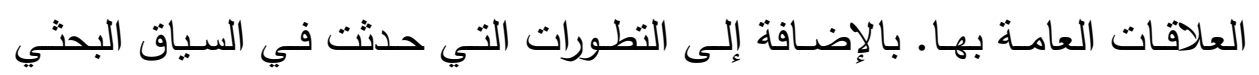

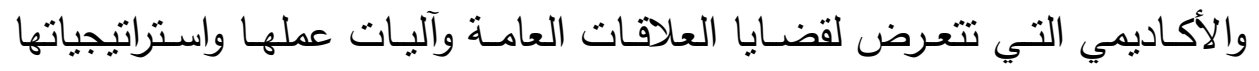
الحديثة الهادفة إلى النهوض بواقعها التقليدي .

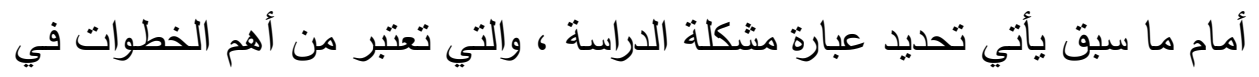
الدراسة وتأتى أهميتها في تحديد الخطوات المنهجية وكذلك في تحديد البيانات التي

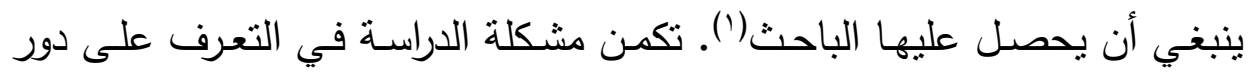

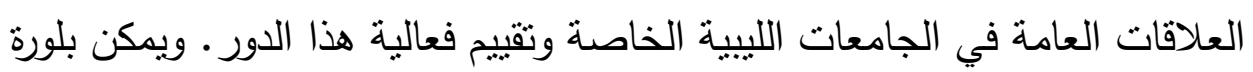

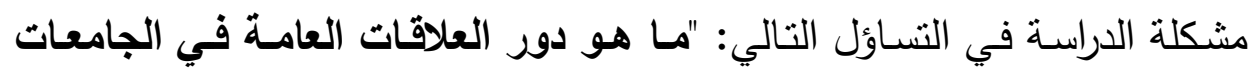




\section{أهمية الدراسة}

تكمن أهيـة الدراسـة في معرفة تقييم دور العلاقات العامة في الجامعات الليبية

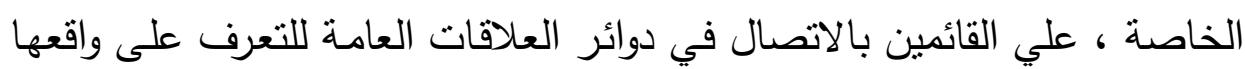

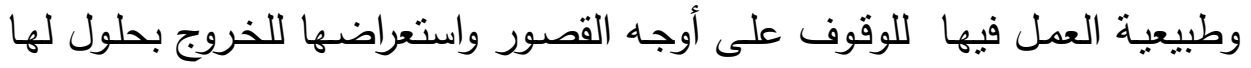

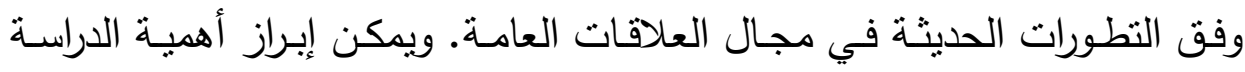

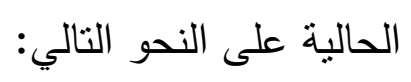
أولاً: الأهمية النظرية: علية النو التئي

ا ـ السـعي نحو إثراء الدراسـات النظريـة الخاصـة بموضـوع العلاقات العامـة

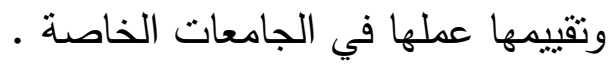

r. بداثة الدراسة لدى المجتمع الليبي.

r. محاولة إبراز الدور الذي يلعبه القائم بالاتصـال في دوائر العلاقات العامة ، واستعراض برامج عملها في الجامعات الخاصة الليبية.

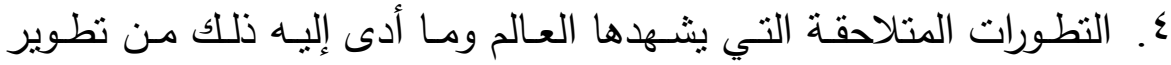
برامج العلاقات العامة في المؤسسات ، والاتجاهات العالمية الحديثة نحو لئه

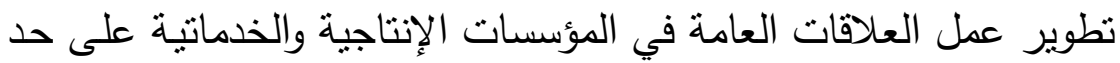
سواء. 


\section{ثنانياً: الأهمبة العملية:-}

ا. تتطلع هذه الدراسة إلى زيادة فاعلية العلاقات العامة في الجامعات الليبية

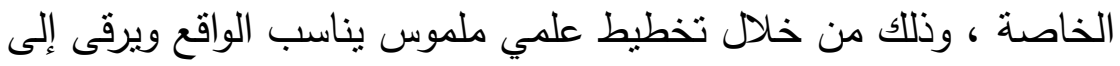
مستوى الطموحات لدى الجامعات الليبية الخاصة.

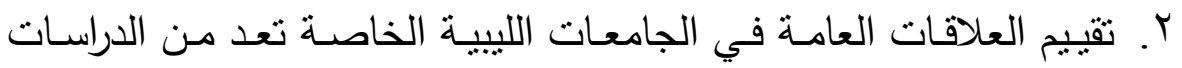

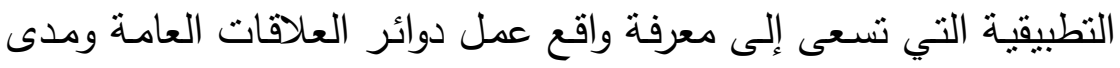
ممارستها لدورها المنوط بها في تلك العملية الهامة.

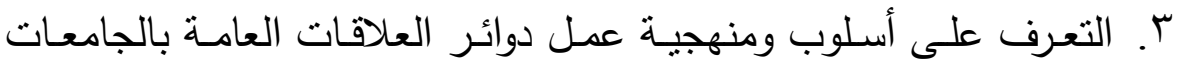

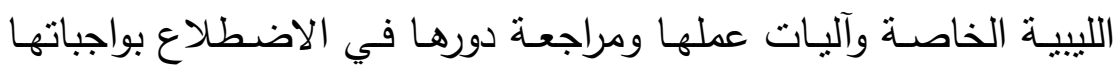

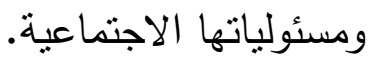

\section{أهداف الاراسة}

تسعى هذه الدراسة إلى تحقيق هدف رئيسي هو دراسة وتقييم دور العلاقات العامة

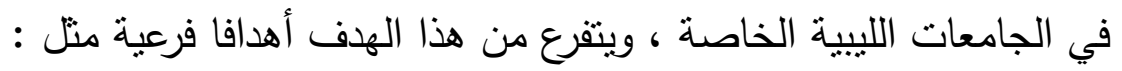
1 - التعـرف على التنظيم الإداري العلافـات العامـة في الجامعـات الليبيـة

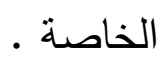
r - التعرف على مدى التزام ممارسي العلاقات العامة في الجامعات اللبيية الخاصة بقواعد إدارة السمعة والصورة.

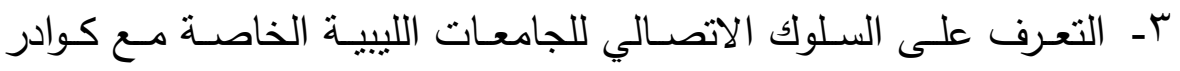

$$
\text { العلاقات العامة. }
$$

ع - التعرف على وسائل العلاقات العامة في الجامعات لتحقيق أهدافها وتفعيل 
○ـ التعرف على المشاكل والصعوبات التي تواجه ممارسي العلاقات العامة في الجامعات الليبية الخاصة. تساؤلات الدراسة الخاصة بممارسي العلاقات العامة

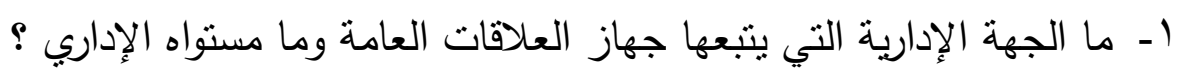

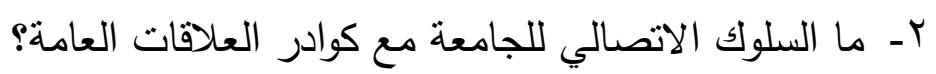

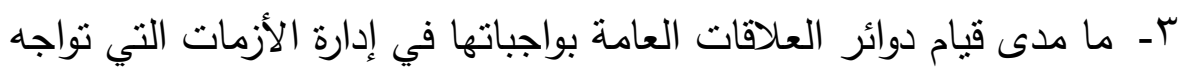
الجامعات الليبية الخاصة؟ ع - ما هي الممارسات الفعلية لعملية العلاقات العامة في الجامعات الليبية الخاصة؟ ○ـ مـا مدى رضـا إدارات العلاقات العامة عن دعم الإدارة العليا لأدائها في الجهاز؟

\section{نوع ومنهج الاراسة :}

تعتبر هذه الدراسة من الدراسات الوصفية ، والمنهج الوصفي هو منهج يعبر عن

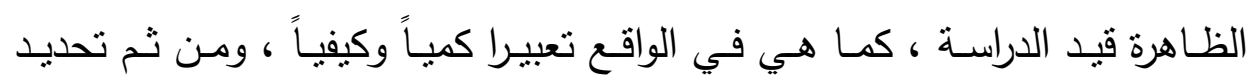

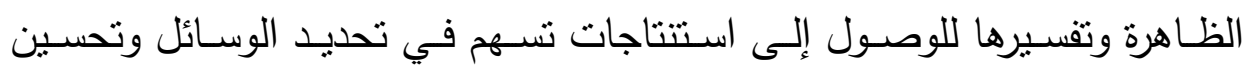

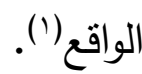
ويعد منهج المسح الإعلامي من أهم المناهج التي تعتمد عليها البحوث الوصفية في الحصول على كافة البيانات والمعلومات.

\section{مجتمع وعينة الدراسة :}

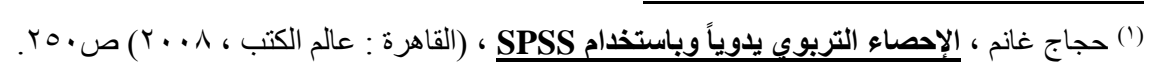


يتمنل مجتمع الدراسة في جميع إدارات العلاقات العامة بالجامعات الليبية الخاصة ، على مستوى الدولة ، وتتمنل في جميع ممارسي العلاقات العامة.

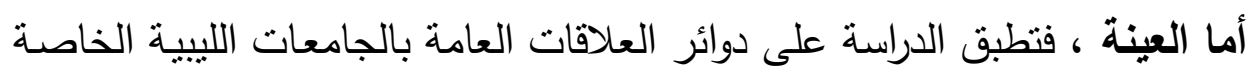

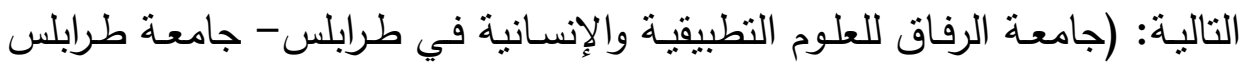

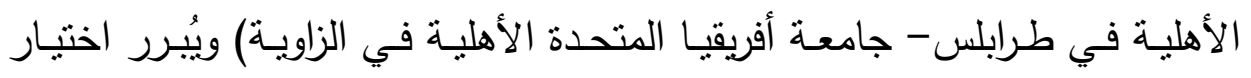

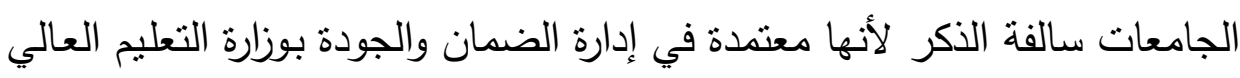
اللليبية .

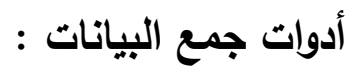
أستمارة الاستنيان

توفر استمارة الاستبيان إمكانية جمع البيانات الخاصة بهذا البحث إضافة لأنها من أكثر أدوات جمع البيانات الأولية استخداما في الدراسات المسحية ، ولإمكانياتها

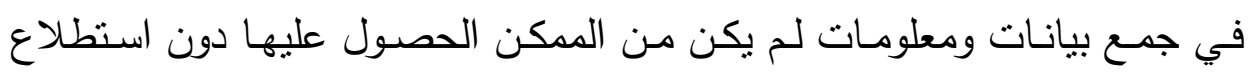

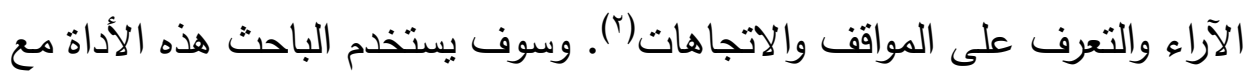

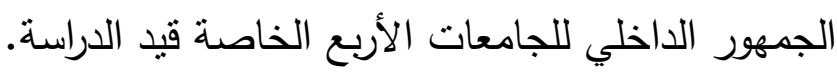

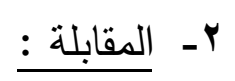

تعتمد على مقابلة الباحث مع عدد من المبحوثين في الجامعات الأربع ، وهي أداة تستخدم في جمع البيانات التي تمكن الباحث من الإجابة على تساؤلات الدراسة. 
نتائج الدراسة:

جدول رقم (1)

تكرارات ونسب عينة الدراسة () ن=9)

\begin{tabular}{|c|c|c|c|c|}
\hline$\%$ & ك & \multicolumn{3}{|c|}{ المتغيرات الديموجرافية } \\
\hline ؛ $\leqslant$. & $\varepsilon$ & \multicolumn{2}{|c|}{ جامعة الرفاق للعظوم التطبيقية } & \multirow{3}{*}{$\overline{7}$} \\
\hline rt.r & r & \multicolumn{2}{|c|}{ جامعة إفريقيا المتحدة الأهلية } & \\
\hline ( & $r$ & \multicolumn{2}{|c|}{ جامعة طرابلس الأهلية بطرابلس } & \\
\hline VV.A & $v$ & \multicolumn{2}{|c|}{ 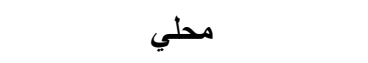 } & \multirow{3}{*}{$\begin{array}{l}\text { 势 } \\
\overline{3} \\
\overline{3}\end{array}$} \\
\hline · & $\cdot$ & \multicolumn{2}{|c|}{ عربي } & \\
\hline rr.t & r & \multicolumn{2}{|c|}{ 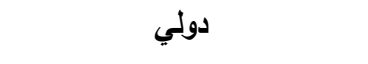 } & \\
\hline 00.7 & $\bullet$ & \multicolumn{2}{|c|}{ ذكور } & \multirow{2}{*}{ 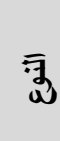 } \\
\hline \& & $\varepsilon$ & \multicolumn{2}{|c|}{ أنثي } & \\
\hline . & . & \multicolumn{2}{|c|}{ أقل من ثانوية عامة } & \multirow{5}{*}{ 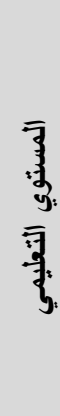 } \\
\hline 11.1 & 1 & & & \\
\hline · & . & & 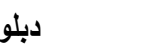 & \\
\hline r & $r$ & & & \\
\hline 00.7 & $\bullet$ & \multicolumn{2}{|c|}{ دراسات عليا (ماجستير /دكتوراه) } & \\
\hline rr.r & r & 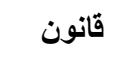 & \multirow[t]{2}{*}{ نظري } & \multirow{2}{*}{ 可 } \\
\hline 11.1 & 1 & اقتصاد & & \\
\hline
\end{tabular}




\begin{tabular}{|c|c|c|c|c|c|}
\hline r.r.r & $r$ & الادارة & \multirow{3}{*}{ علي } & & \\
\hline r.r.r & $r$ & 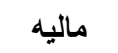 & & & \\
\hline 11.1 & 1 & هندسة & & & \\
\hline rt.r & r & \multicolumn{2}{|c|}{ من سنة لأقل من ساسنوات } & \multirow{3}{*}{\multicolumn{2}{|c|}{ 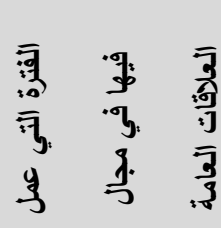 }} \\
\hline 11.1 & 1 & \multicolumn{2}{|c|}{ من بالأقل من هسنوات } & & \\
\hline หั. & 7 & \multicolumn{2}{|c|}{ أكثر من خمس سنوات } & & \\
\hline
\end{tabular}

يوضح الجدول السابق المتغيرات الديموجرافية من حيث الجامعة ونطاق العمل

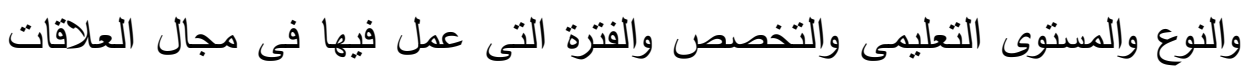

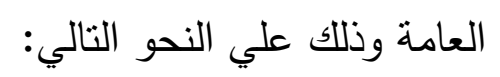

1- خصائص عينة الاراسة وفقاً للجامعة : توزعت عينة الدراسة حيث كانت فى المقدمة (جامعة الرفاق للعلوم التطبيقية والإنسانية بطرابلس) بنسبة ؟. ؟ ٪ ، ثم فى المرتبة الثانية (جامعة طرابلس

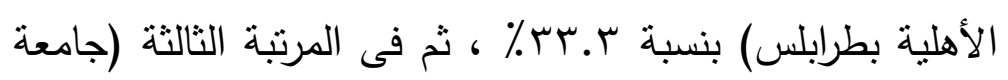

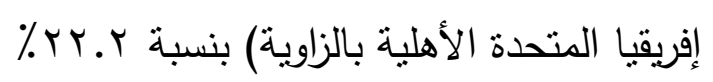

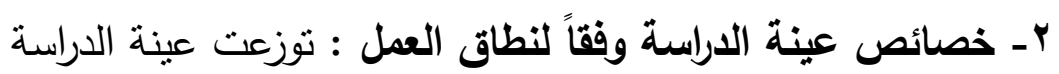

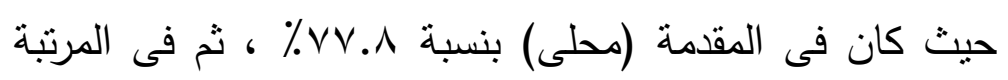

$$
\text { الثانية (دولى) بنسبة r.r.r. }
$$

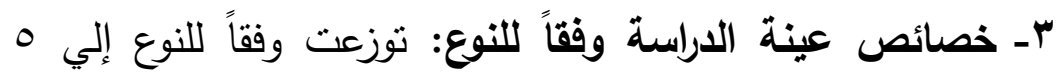
مفردة من الذكور بنسبة بلغت 00.7٪ في مقابل ؛ مفردة من الإناث بنسبة بلغت ع. ؟ ؟ ٪. 
؛- خصائص عينة الدراسة وفقاً للمستوى التعليمى : يتضح أن

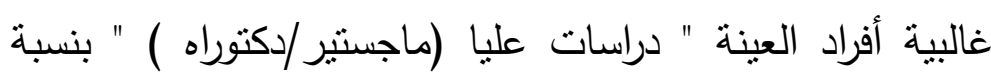

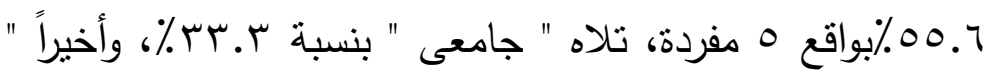

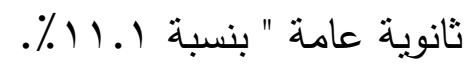
هـ - خصائص عينة الاراسة وفقاً للتخصص : بالنسبة للنظرى حيث

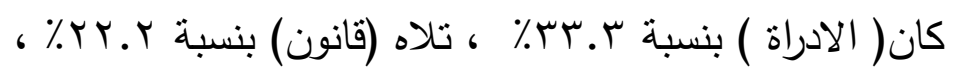
ז- خصائص عينة الاراسة وفقاً للفترة التى عمل فيها فى مجال العلاقات العامة : حيث كان فى المقدمة ( أكثر من خمس سنوات

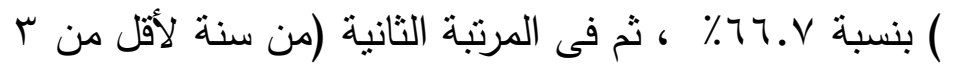

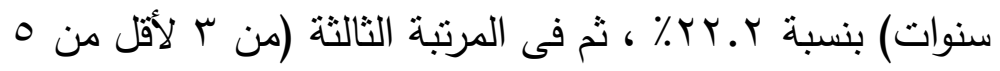

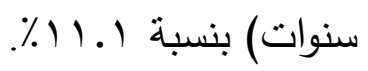




\section{جدول رقم (r)}

مدي وجود جهاز متخصص لممارسة أنشطة العلاقات في جامعة

افراد العينة وفقاً للجامعة

\begin{tabular}{|c|c|c|c|c|c|c|c|c|}
\hline \multicolumn{2}{|c|}{ الإجمالي } & \multicolumn{2}{|c|}{ بالز اوية } & \multicolumn{2}{|c|}{ طرايلس } & \multicolumn{2}{|c|}{ الرفاق } & نوع العينة \\
\hline$\%$ & ك & $\%$ & ك & $\%$ & ك & $\%$ & s & ددي وجود \\
\hline $1 \ldots$ & 9 & $1 \ldots$ & r & $1 \ldots$ & $\varepsilon$ & $1 .$. & $r$ & نعم \\
\hline - & - & - & - & - & & - & - & ע \\
\hline $1 \ldots$ & 9 & $1 \ldots$ & $r$ & $1 \ldots$ & $\varepsilon$ & $1 \ldots$ & $r$ & المجموع \\
\hline
\end{tabular}

يوضح الجدول السابق مدي وجود جهاز متخصص لممارسة أنشطة العلاقات في

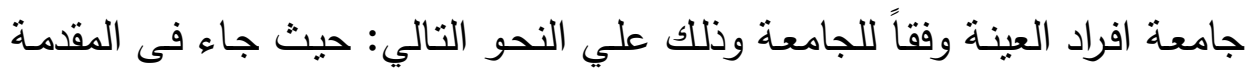

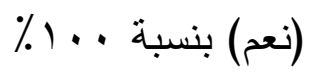




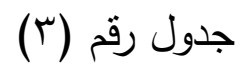

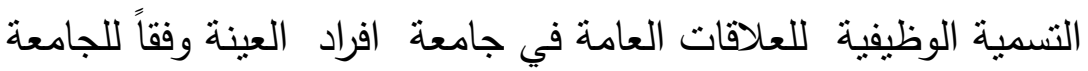

\begin{tabular}{|c|c|c|c|c|c|c|c|c|}
\hline \multicolumn{2}{|c|}{ الإجمالي } & \multicolumn{2}{|c|}{ بالز اوية } & \multicolumn{2}{|c|}{ طرابلس } & \multicolumn{2}{|c|}{ الرفاق } & نوع العينة \\
\hline$\%$ & ك & $\%$ & ك & $\%$ & ك & $\%$ & s & التسمية \\
\hline rr.r & $r$ & - & - & - & - & $1 \ldots$ & $r$ & العلاقات العامة \\
\hline- & - & - & - & - & - & - & - & الثؤون العامة \\
\hline- & - & - & - & - & - & - & - & العلاقات العامة والاتصالات \\
\hline- & - & - & - & - & - & - & - & العلاقات العامة والإعلام \\
\hline- & - & - & - & - & - & - & - & العلاقات العامة والإعلان \\
\hline Tr.Y & r & $1 \cdots$ & r & - & - & - & - & العلاقات العامة والخدمات \\
\hline- & - & - & - & - & - & - & - & التسويق والعلاقات العامة \\
\hline 纟ะ. & $\varepsilon$ & - & - & $1 \ldots$ & $\varepsilon$ & . & 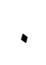 & الثئون الادارية \\
\hline $1 \ldots$ & 9 & $1 \ldots$ & r & $1 \ldots$ & $\varepsilon$ & $1 \ldots$ & r & المجموع \\
\hline
\end{tabular}

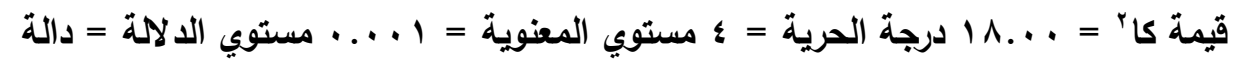

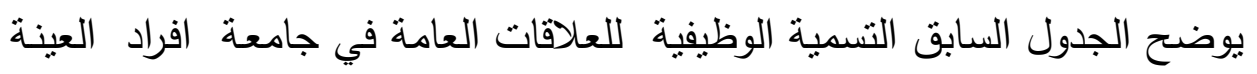
وفقاً للجامعة وذلك علي النحو التالي:

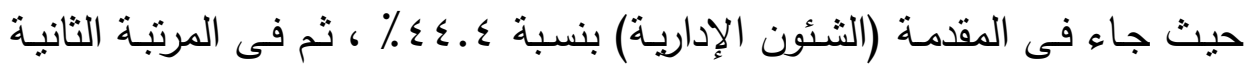

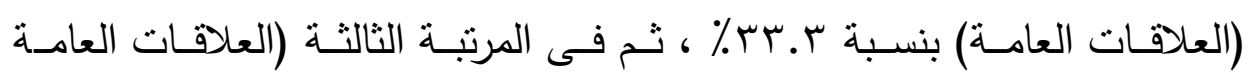

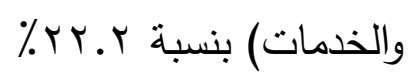

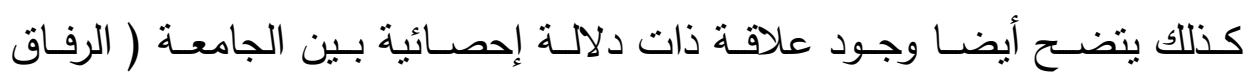

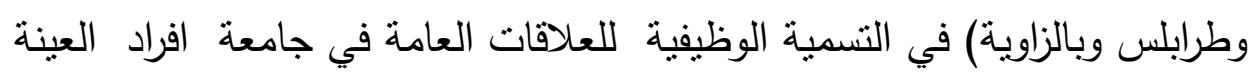
، حيث كانت قيمه كاب = . ...1 عند درجة الحرية (ع) وهي دالة إحصائيا. 


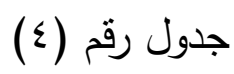

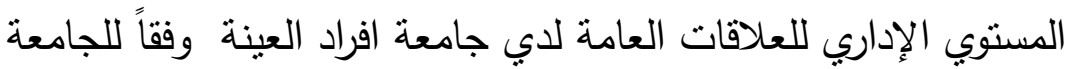

\begin{tabular}{|c|c|c|c|c|c|c|c|c|}
\hline \multicolumn{2}{|c|}{ الإجمالي } & \multicolumn{2}{|c|}{ بالز اوية } & \multicolumn{2}{|c|}{ طرابلس } & \multicolumn{2}{|c|}{ الرفاق } & \multirow[t]{2}{*}{ نوع العينة } \\
\hline$\%$ & ك & $\%$ & ك & $\%$ & ك & $\%$ & ك & \\
\hline - & - & - & - & - & - & - & - & قطاع \\
\hline - & - & - & - & - & - & - & - & جهاز \\
\hline - & - & - & - & - & - & - & - & إدارة عامة \\
\hline - & - & - & - & - & - & - & - & إدارة \\
\hline TY.T & r & $1 \ldots$ & $r$ & - & - & - & - & قسم \\
\hline$V \vee . \wedge$ & v & - & - & $1 \ldots$ & $\varepsilon$ & $1 \ldots$ & $r$ & مكتب \\
\hline - & - & - & - & - & - & - & - & وحدة \\
\hline- & - & - & - & - & - & - & - & شعبة \\
\hline $1 \ldots$ & 9 & $1 \ldots$ & $r$ & $1 \ldots$ & $\varepsilon$ & $1 \ldots$ & $r$ & المجموع \\
\hline
\end{tabular}

يوضح الجدول السابق المستوي الإداري للعلاقات العامة لدي جامعة افراد العينة وفقاً للجامعة وذللك علي النحو التالي:

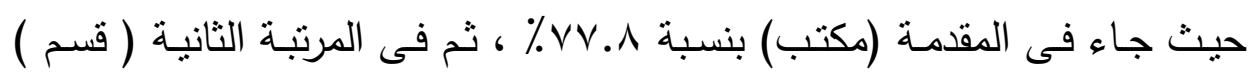
بنسبة Y.r. 
جدول رقم (0) - (0)

الرئاسة الإدارية المباشرة للعلاقات العامة لدي افراد العينة وفقاً للجامعة

\begin{tabular}{|c|c|c|c|c|c|c|c|c|}
\hline \multicolumn{2}{|c|}{ الإجمالي } & \multicolumn{2}{|c|}{ بالز اوية } & \multicolumn{2}{|c|}{ طرابلس } & \multicolumn{2}{|c|}{ الرفاق } & \multirow[t]{2}{*}{ نوع العينة } \\
\hline$\%$ & كs & $\%$ & ك & $\%$ & s & $\%$ & ك & \\
\hline rr.r & r r & $1 \cdots$ & r & - & - & - & - & رئيس الجامعة \\
\hline- & - & - & - & - & - & - & - & نائب رئيس الجامعة \\
\hline 11.1 & 1 & - & - & ro & 1 & - & - & الأمين العام \\
\hline- & - & - & - & 0. & $r$ & - & - & الأمين العام المساعد \\
\hline 11.1 & 1 & - & - & ro & 1 & - & - & الدير العام \\
\hline- & - & - & - & - & - & - & - & نائب المدير العام \\
\hline- & - & - & - & - & - & - & - & 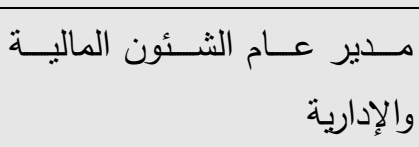 \\
\hline rT.r & $r$ & - & - & - & - & $1 \cdots$ & $r$ & مدير الثئون الإدارية \\
\hline- & - & - & - & - & - & - & - & مدير إدارة النسويق \\
\hline $1 \ldots$ & 9 & $1 \ldots$ & r & $1 \ldots$ & $\varepsilon$ & $1 \ldots$ & $r$ & المجموع \\
\hline
\end{tabular}

يوضح الجدول السابق الرئاسة الإدارية المباشرة للعلاقات العامة لدي افراد العينة وفقاً للجامعة وذللك علي النحو التالي:

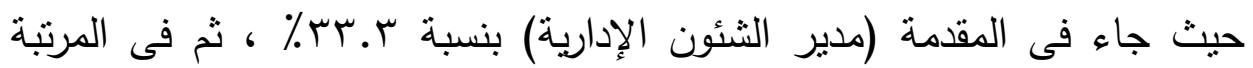

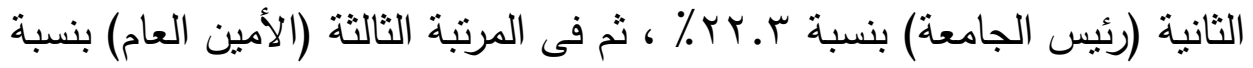

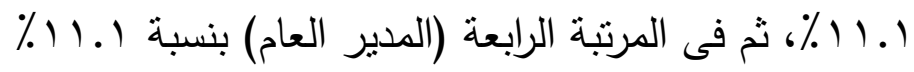




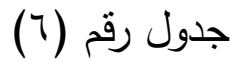

عدد العاملين بالعلاقات العامة في الجامعة لتي تعمل بها وفقاً للجامعة

\begin{tabular}{|c|c|c|c|c|c|c|c|c|}
\hline \multicolumn{2}{|c|}{ الإجمالي } & \multicolumn{2}{|c|}{ بالز اوية } & \multicolumn{2}{|c|}{ طرابلس } & \multicolumn{2}{|c|}{ الرفاق } & \multirow{2}{*}{ دور } \\
\hline$\%$ & ك & $\%$ & ك & $\%$ & ك & $\%$ & ك & \\
\hline rT.r. & r r & . & . & ro & 1 & $4 \pi, V$ & r r & القرار . المــاركة فـي عمليـة اتخــاذ \\
\hline - & - & - & - & - & - & - & - & لمجلس الجامعة. \\
\hline $74, V$ & 7 & $1 \ldots$ & r & vo & $r$ & rr, & 1 & 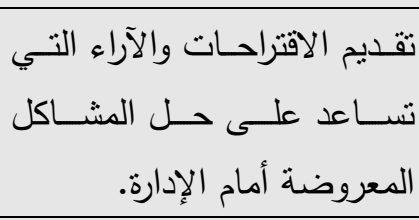 \\
\hline- & - & - & - & - & - & - & - & مجلس الجامعة. \\
\hline- & - & - & - & - & - & - & - & تحتليل القرارات التي يتم اتخاذها \\
\hline $1 \ldots$ & 9 & $1 \ldots$ & $r$ & $1 \ldots$ & $\varepsilon$ & $1 \ldots$ & $r$ & المجموع \\
\hline
\end{tabular}

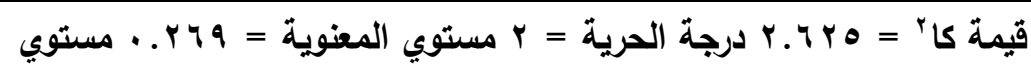

$$
\text { الد لالة =غير دالة }
$$

يوضح الجدول السابق دور القائم بالاتصال في العلاقات العامة سواء في الجامعة

$$
\text { أو العلاقات العامة وفقاً للجامعة وذللك علي النحو النالي: }
$$

حيث جاء فى المقدمة (تقديم الاقتراحات والآراء التي تساعد على حل المشاكل

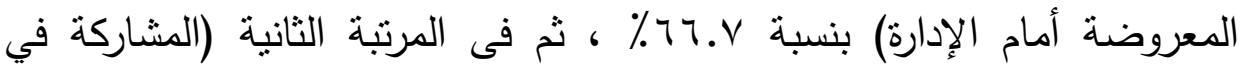




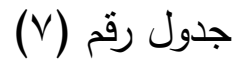

القنوات الاتصالية الداخلي (تقارير ، خطابات ،لقاءات مفتوحة ،ذدوات

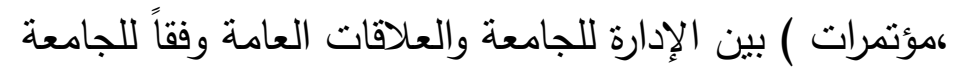

\begin{tabular}{|c|c|c|c|c|c|c|c|c|}
\hline \multicolumn{2}{|c|}{ الإجمالي } & \multicolumn{2}{|c|}{ بالز اوية } & \multicolumn{2}{|c|}{ طرابلس } & \multicolumn{2}{|c|}{ الرفاق } & \multirow{2}{*}{ القنوات الاتصالية نوع العينة } \\
\hline$\%$ & ك & $\%$ & ك5 & $\%$ & ك & $\%$ & ك & \\
\hline$V V .7$ & v & . & . & $1 \ldots$ & $\varepsilon$ & $1 \ldots$ & $r$ & منفتحة تماماً \\
\hline YY,Y & $r$ & $1 \cdots$ & $r$ & - & - & - & - & منظقة إلي حدما \\
\hline & 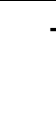 & - & - & - & - & - & - & 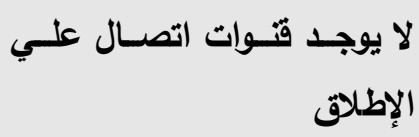 \\
\hline $1 \ldots$ & 9 & $1 \ldots$ & r & $1 \ldots$ & $\varepsilon$ & $1 \ldots$ & $r$ & المجموع \\
\hline
\end{tabular}

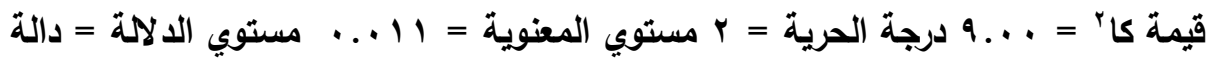

يوضـح الجدول السـابق القنوات الاتصـالية الداخلي (تقارير ، خطابـات ،لقاءات

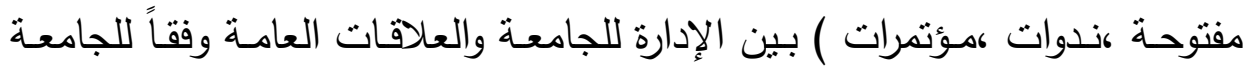
وذلك علي النحو التالي: مفتح

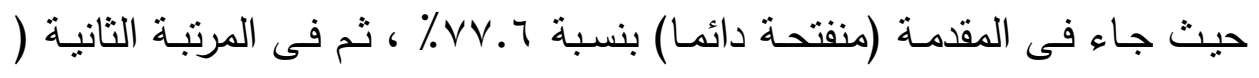

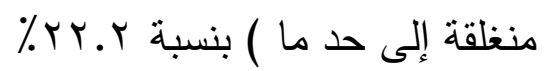

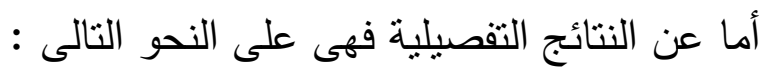
ا بالنسبة للرفاق

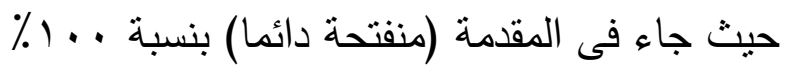

$$
\begin{aligned}
& \text { r- بالنسبة لطرابلس } \\
& \text { حيث جاء فى المقدمة (منفتحة دائما) بنسبة . . ٪ }
\end{aligned}
$$




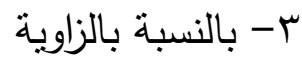

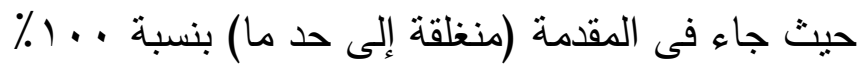

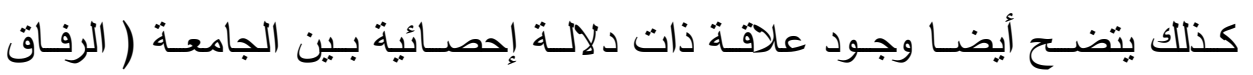

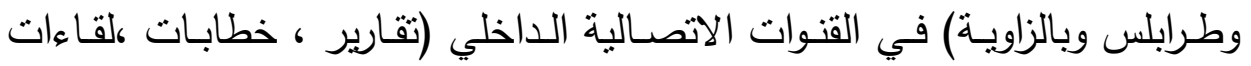
مفتوحة ،ندوات ،مؤنمرات ) بين الإدارة للجامعة والعلاقات العامـة ، حيث كانت قيمه كاب = ... . عند درجة الحرية (r) وهي دالة إحصائيا.

جدول رقم (^)

مدي تتبع العلاقات العامة وإدارة الجامعة الأساليب التالية

\begin{tabular}{|c|c|c|c|c|c|c|c|c|c|c|}
\hline \multirow{2}{*}{ 零. } & \multirow{2}{*}{ 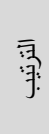 } & \multirow{2}{*}{$=$} & \multirow{2}{*}{ 高 } & \multicolumn{2}{|c|}{ معارض } & \multicolumn{2}{|c|}{ محايد } & \multicolumn{2}{|c|}{ موافق } & \multirow[b]{2}{*}{ العبارات } \\
\hline & & & & $\%$ & ك & $\%$ & ك & $\%$ & ك5 & \\
\hline & 1 & $r$ & $T V$ & . & . & . & . & $1 \ldots$ & 9 & 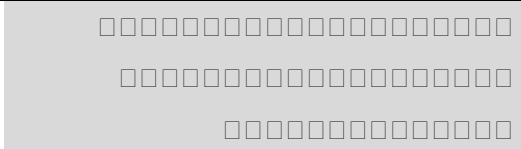 \\
\hline & r & $\begin{array}{l}r . \\
\wedge\end{array}$ & ro & . & . & Y..Y & $r$ & VV.A & v & 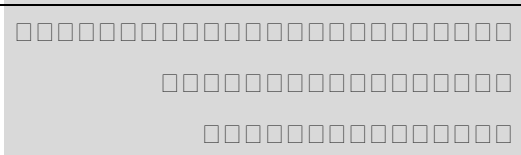 \\
\hline & $r$ & $\begin{array}{l}r . \\
r\end{array}$ & $r \varepsilon$ & . & . & א.זT & $r$ & 4.. & 7 & 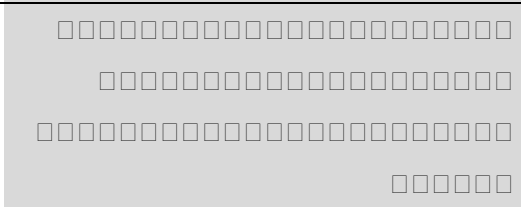 \\
\hline & 1 & $r$ & $T V$ & . & . & . & . & $1 \ldots$ & 9 & 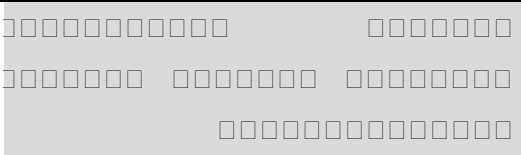 \\
\hline & $\varepsilon$ & $\begin{array}{l}\text { r. } \\
\varepsilon\end{array}$ & rY & . & . & 00.7 & 0 & 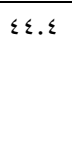 & $\varepsilon$ & 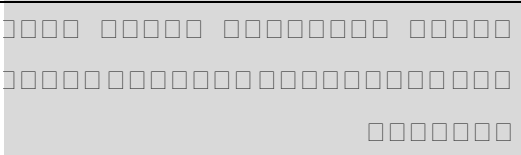 \\
\hline & 7 & $\begin{array}{l}1 . \\
9\end{array}$ & IV & 11.1 & 1 & $1 \wedge .9$ & $\wedge$ & . & . & 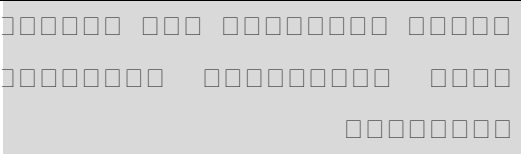 \\
\hline & 9 & 1. & 1. & $\wedge \wedge .9$ & $\wedge$ & 11.1 & 1 & . & . & 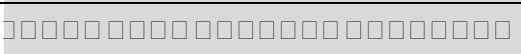 \\
\hline
\end{tabular}




\begin{tabular}{|c|c|c|c|c|c|c|c|c|c|c|}
\hline \multirow{2}{*}{ 离 } & \multirow{2}{*}{ 高 } & & \multirow{2}{*}{ 雹 } & \multicolumn{2}{|c|}{ معارض } & \multicolumn{2}{|c|}{ محايد } & \multicolumn{2}{|c|}{ موافق } & \multirow[b]{2}{*}{ العبارات } \\
\hline & & & & $\%$ & ك & $\%$ & ك & $\%$ & ك & \\
\hline & & 1 & & & & & & & & 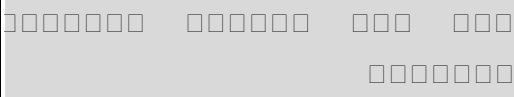 \\
\hline & $\bar{v}$ & $\begin{array}{l}1 . \\
r\end{array}$ & Kr & TI. & 1 & Tr.r & $r$ & . & . & 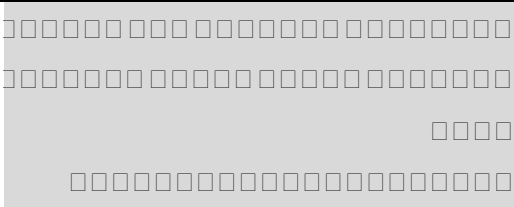 \\
\hline & 0 & $\begin{array}{l}r . \\
\text { r. }\end{array}$ & 19 & 11.1 & 1 & Tr.V & 1 & YY.Y & $r$ & 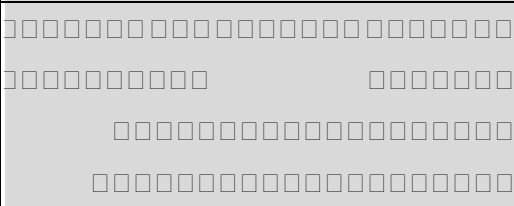 \\
\hline & $\wedge$ & $\begin{array}{l}1 . \\
r\end{array}$ & 11 & $Y Y \cdot A$ & v & r.r.r & $r$ & . & . & 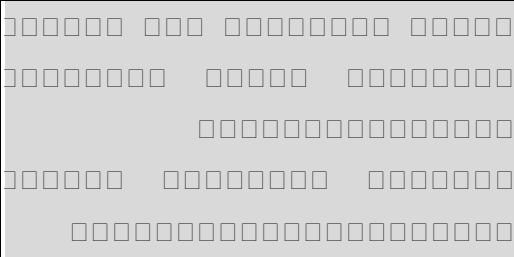 \\
\hline
\end{tabular}

يوضتح الجدول السابق مدي تتبع العلاقات العامة وإدارة الجامعة الأساليب التالية

$$
\text { وذللك على النحو التالى : }
$$

ا ـ لاى العلاقات العامة أهداف محددة مرتبطة بأهداف الجامعة :

حيث كان موافق بنسبة . . 1 ، وذلك بمنتسط ب

r- الأنشطة الاتصالية للعلاقات العامة ترتبط بأهداف الجامعة :

حيث كان موافق بنسبة . 1 \% ، وذلك بمتوسط ب 
r- إدارة الجامعة تستقيد من الخطط التي تضعها العلاقات العامة :

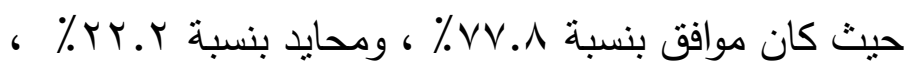

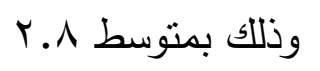

ع - إدارة الجامعة قد تغير من أهدافها بناء على دراسات تجريها

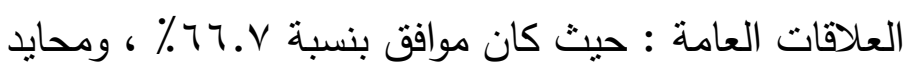

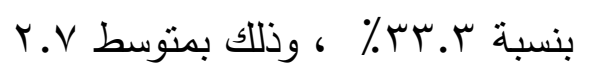

0ـ إدارة الجامعة تعدل من خطط العلاقات العامة بعد تتفيذها : حيث

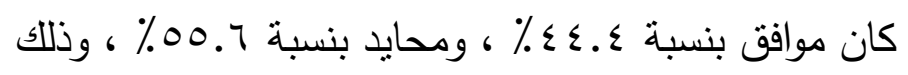

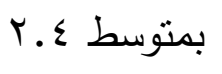

7- لا يوجد اهتمام من إدارة الجامعة بالأنشطة الاتصالية التي تقوم

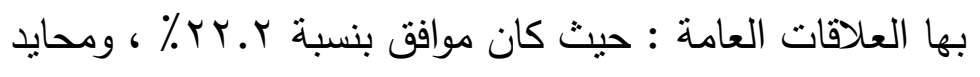

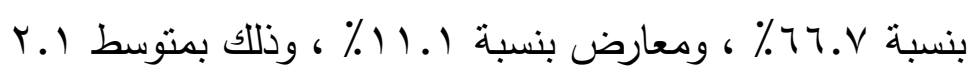
V- إدارة الجامعة لا تهتم بخطط العلاقات العامة وأنشطتها : حيث

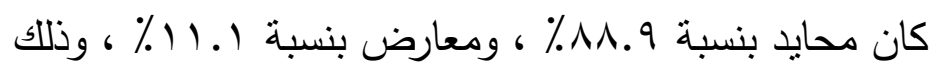

$$
\text { بمنوسط } 1.9
$$

ᄉـ العلاقات العامة لا تحدد أهدافها ولكن تتفذ الخطط التي تضعها

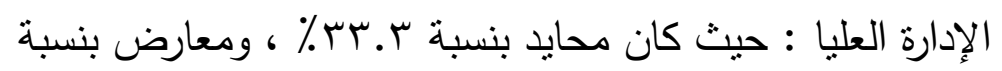

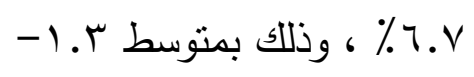


9 - إدارة الجامعة لا تهتم بالأبحاث التي تجريها العلاقات العامة

لتطوير الأهداف التي تسعى لتحقيقها الجامعة : حيث كان محايد

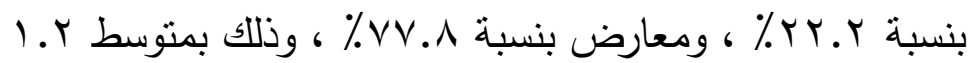

• - ـ العلاقات العامة ليس لها دور في تحديد أهداف الجامعة

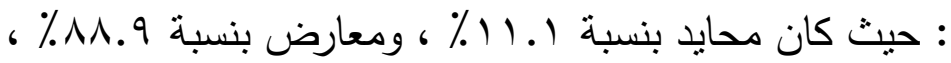

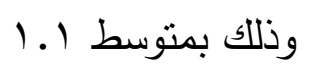

جدول رقم (9) - (9) - (9)

الآليات التي تتعامل بها الجامعة عند مواجهتها للأزمات

\begin{tabular}{|c|c|c|c|c|c|c|c|c|c|c|}
\hline \multirow{2}{*}{ 育. } & \multirow{2}{*}{ 雪 } & \multirow{2}{*}{$\begin{array}{c}\overline{7} \\
\overline{3} \\
\bar{y} \\
\overline{7} \\
\frac{3}{3}\end{array}$} & \multirow{2}{*}{ 司 } & \multicolumn{2}{|c|}{$\bar{y}$} & \multicolumn{2}{|c|}{ أحياناً } & \multicolumn{2}{|c|}{ نعم } & \multirow[b]{2}{*}{ العبارات } \\
\hline & & & & $\%$ & ك & $\%$ & ك & $\%$ & 5 & \\
\hline & $r$ & $\begin{array}{l}\text { r. } \\
r\end{array}$ & $r r$ & . & . & $\varepsilon \varepsilon . \varepsilon$ & $\varepsilon$ & 00.1 & 0 & 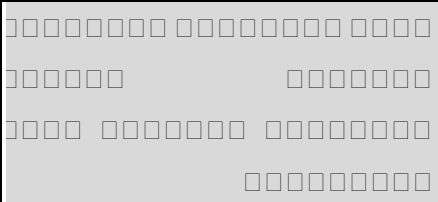 \\
\hline & $r$ & $\begin{array}{l}\text { r. } \\
r\end{array}$ & rr & . & . & 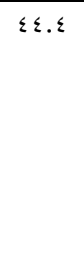 & $\varepsilon$ & 00.1 & 0 & 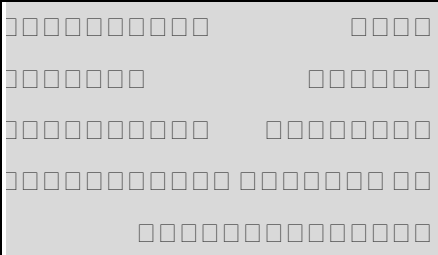 \\
\hline & 1 & $\begin{array}{l}r . \\
r\end{array}$ & $r \varepsilon$ & . & . & Tr.r & $r$ & Ir.V & 1 & 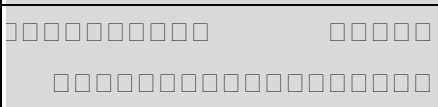 \\
\hline & 0 & $\begin{array}{l}1 . \\
9\end{array}$ & IV & TY.Y & $r$ & T4.V & 7 & 11.1 & 1 & 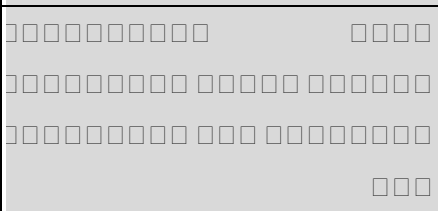 \\
\hline & $\varepsilon$ & $r$ & 11 & 11.1 & 1 & $V V . A$ & v & 11.1 & 1 & 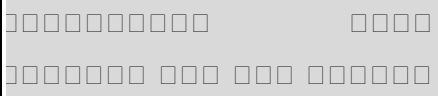 \\
\hline
\end{tabular}




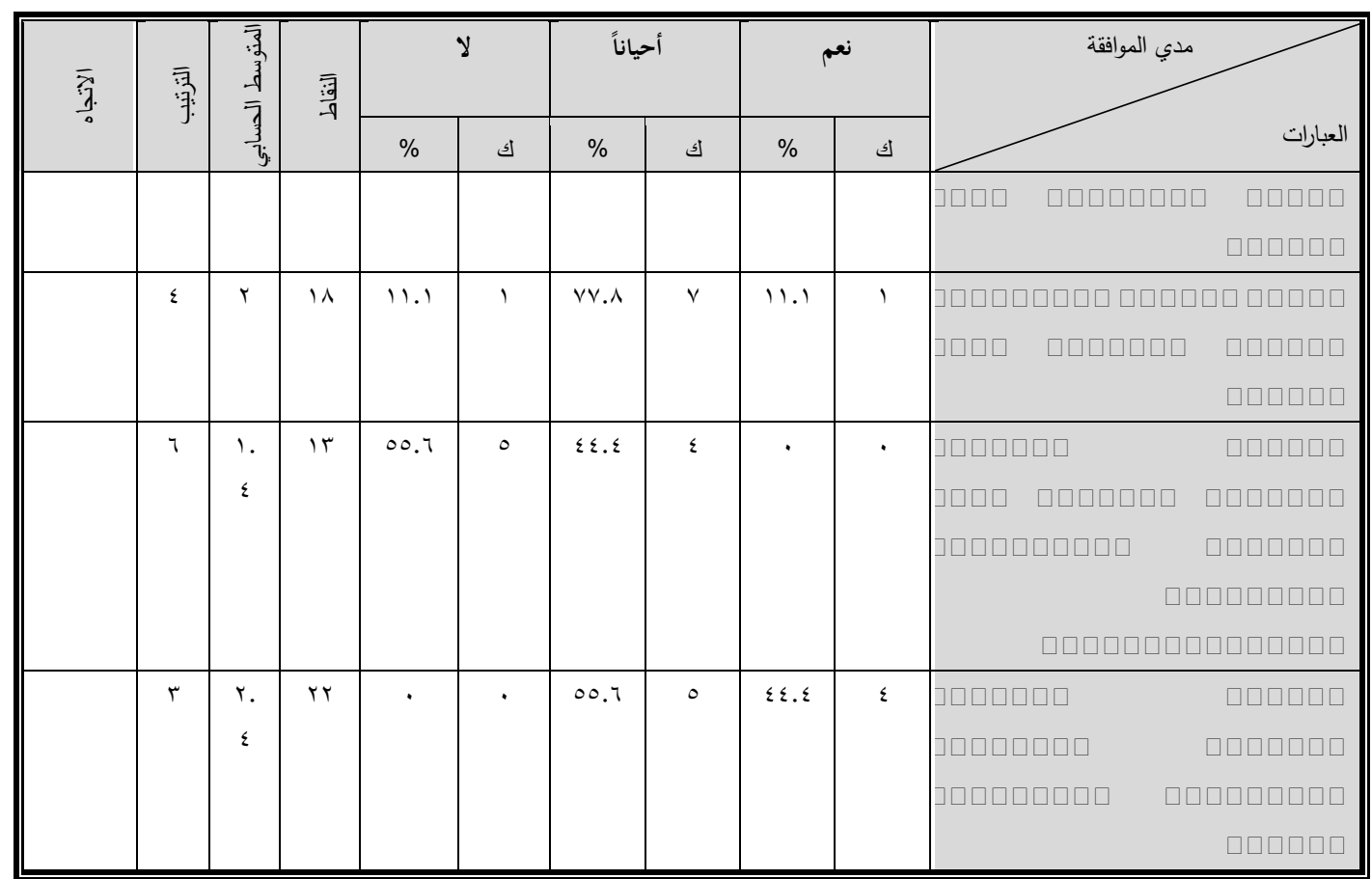

يوضح الجدول السابق الآليات التي تتعامل بها الجامعة عند مواجهتها للأزمات

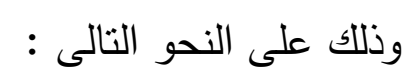

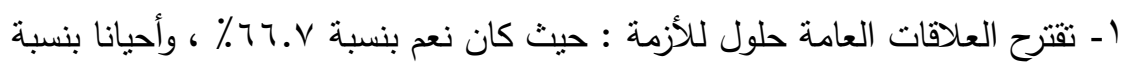

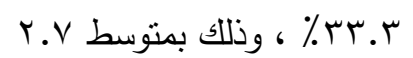

r- تأخذ الإدارة العليا للجامعة برأي العلاقات العامة في حل الأزمة : حيث كان نعم بنسبة

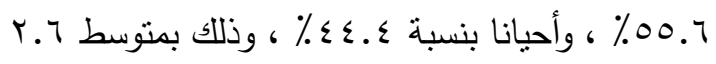

r- تقدم العلاقات العامة نتائج الدراسات والأبحاث من بيانات وإحصائيات للإدارة العليا :

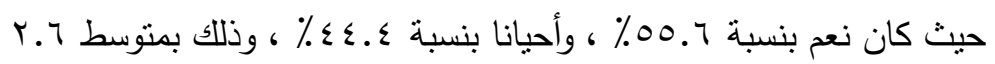

ع- تستعين إدارة الجامعة العليا بمستشارين خارجيين مختصين : حيث كان نعم

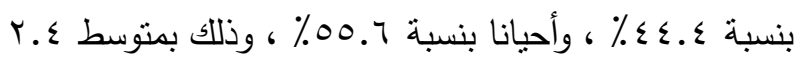


ــ ـ تجمع العلاقات العامة كل ما قدمته وسائل الإعلام عن الأزمة : حيث كان

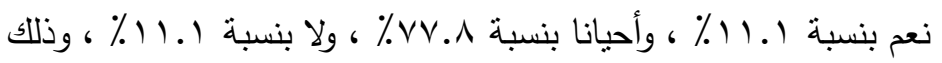

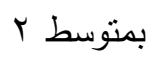

7- تتفرد أدارة الجامعة العليا بإيجاد حل للأزمة : حيث كان نعم بنسبة 1.11\%

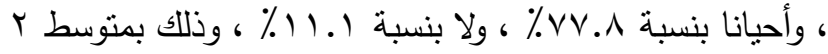

V- تقوم العلاقات العامة بدور المتحدث الإعلامي عن الجامعة فقط : حيث كان

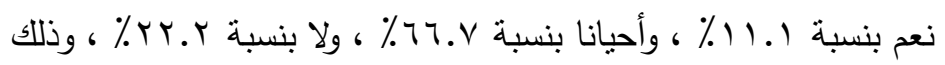

$$
\text { بمنوسط } 1.9
$$

1- تستشير إدارة الجامعة العليا كل الأقسام بالجامعة باستثناء العلاقات العامة :

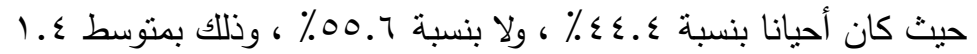

$$
\text { جدول رقم (·) (1) }
$$

\begin{tabular}{|c|c|c|c|c|c|c|c|c|c|c|}
\hline \multirow{2}{*}{ 霉 } & \multirow{2}{*}{ 高: } & \multirow{2}{*}{$\begin{array}{c}\overline{3} \\
3 \\
\frac{7}{7} \\
\overline{7} \\
3 \\
\end{array}$} & \multirow{2}{*}{ 司 } & \multicolumn{2}{|c|}{ معارض } & \multicolumn{2}{|c|}{ محايد } & \multicolumn{2}{|c|}{ موافق } & \\
\hline & & & & $\%$ & ك5 & $\%$ & ك5 & $\%$ & ك & \\
\hline & $r$ & $\begin{array}{l}r . \\
v\end{array}$ & $r \varepsilon$ & . & . & ז.זr & $r$ & T..V & 1 & 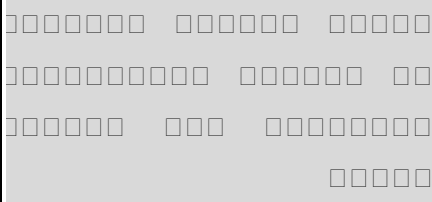 \\
\hline & $r$ & $\begin{array}{l}\text { r. } \\
\text { v. }\end{array}$ & $r \varepsilon$ &. & . & rr.r & $r$ & 4T.V & 7 & 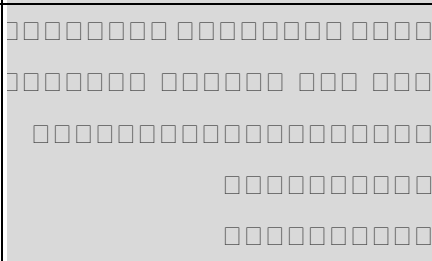 \\
\hline & 1 & $\begin{array}{ll}r \\
\wedge\end{array}$ & ro & . & . & YY.Y & $r$ & VV.A & $\mathrm{V}$ & 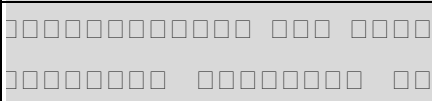 \\
\hline
\end{tabular}

إلي أي مدي وصف العبارات الوظائف المهنية التي تقوم بها كممارس للعلاقات

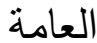




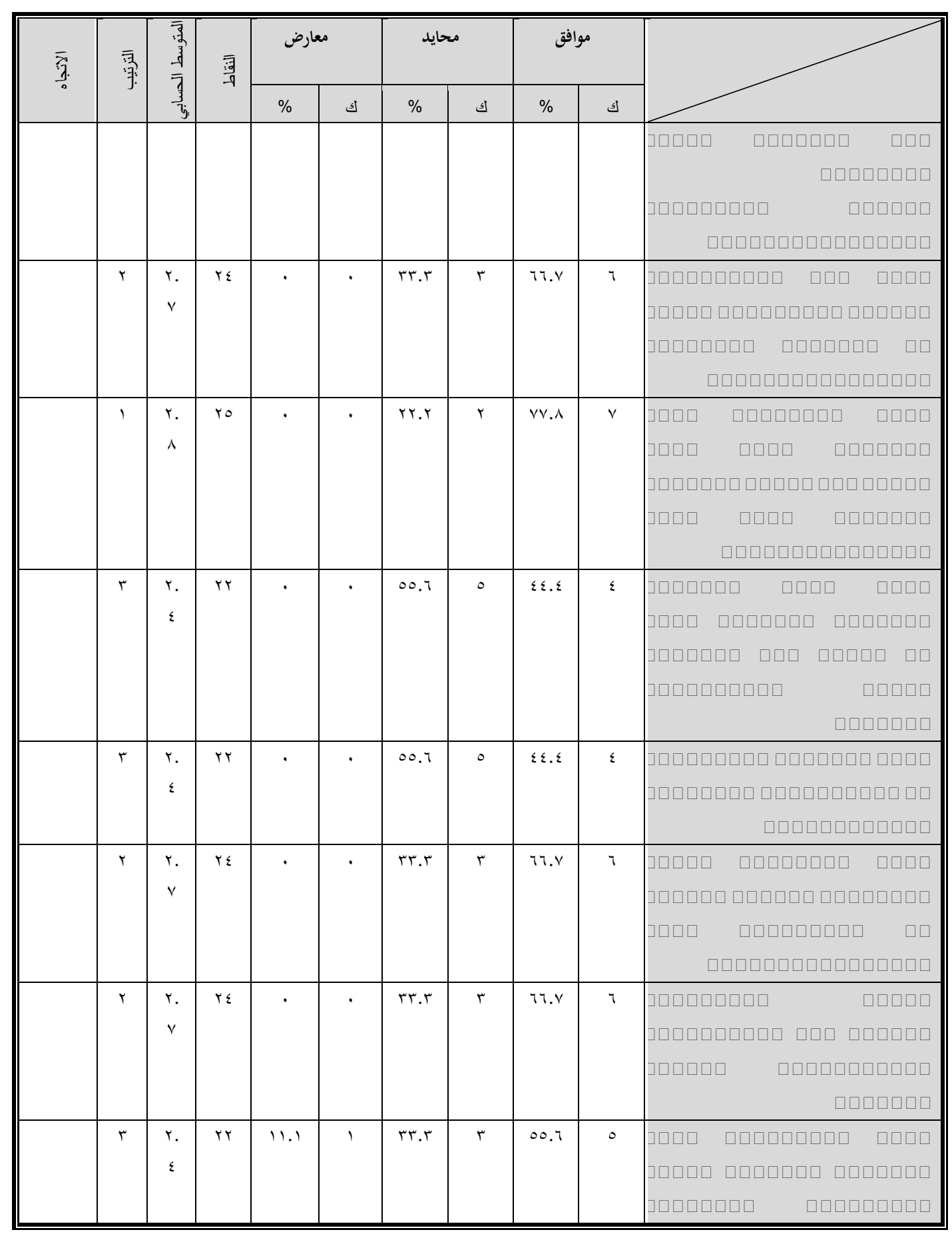




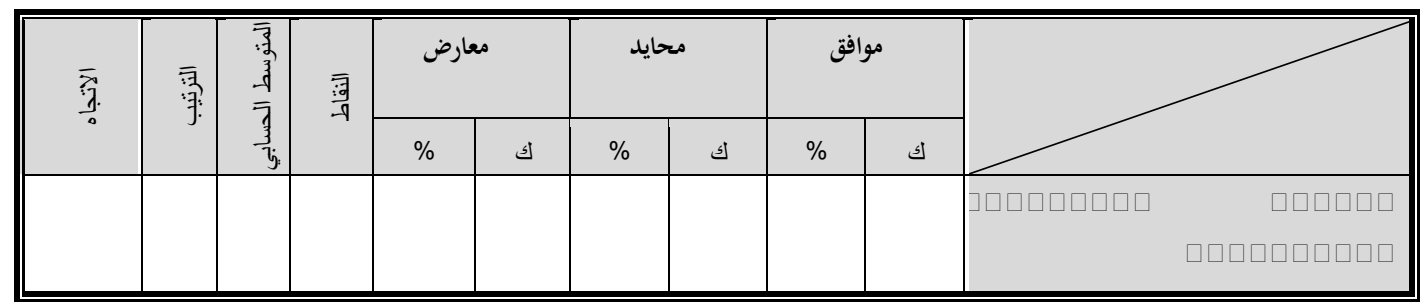

يوضح الجدول السابق إلي أي مدي وصف العبارات الوظائف المهنية التي تقوم بها كمارس للعلاقات العامة وذلك على النحو التالى : ا - أطلع الآخرين في الجامعة على ما تتشره أو تبثه وسائل الإعلام مما له علاقة بالجامعة : حيث كان موافق بنسبة ^.

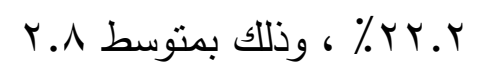

r - أثير في الاجتماعات مع الإدارة العليا إلى الحاجة إلى التخطيط المنظم

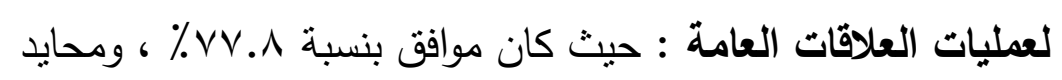

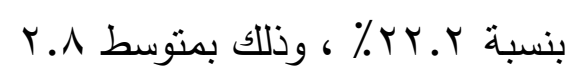

r- أوضت البدائل لحل المشكلات عندما أعمل مع المديرين في العلاقات

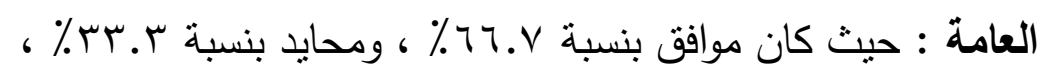

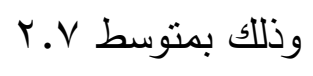

ــ أشارك الإدارة العليا في اللقاءات والاجتماعات التي تعقدها : حيث كان

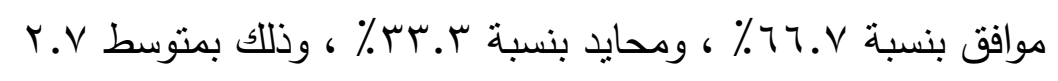

0ـ أتمتع بحرية كاملة في اتخاذ القرارات الإدارية في مجال تخصصي: حيث

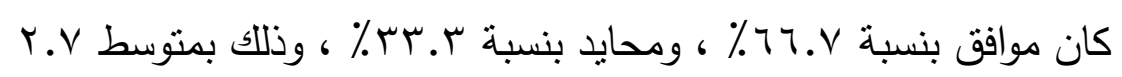

7 - أطلع الإدارة العليا على رد الفعل العام تجاه سباسات الجامعة وخطواتها

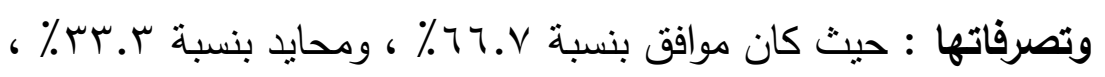

وذللك بمتوسط V. T. 
V - أعمل مع المديرين لزيادة مهاراتهم لحل أو لتلافي مشكلات العلاقات

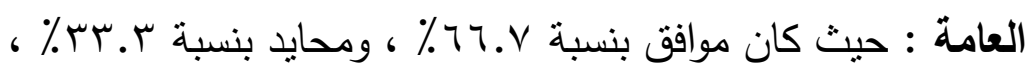

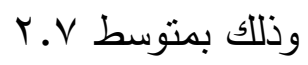

ᄉ- أعمل على إثرالك الإدارة العليا في كل خطوة من خطوات برامج العلاقات

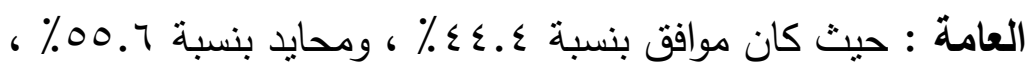

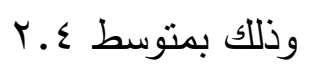

9 ـ أقوم بتمثيل الجامعة في المناسبات العامة والاجتماعات : حيث كان

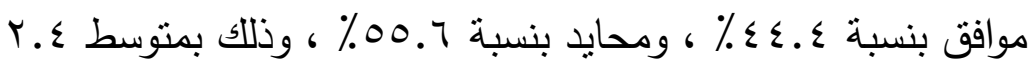

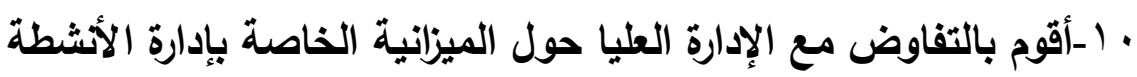

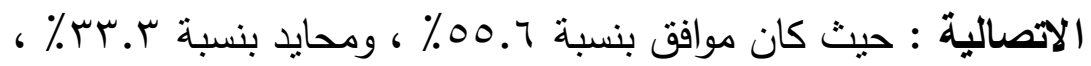

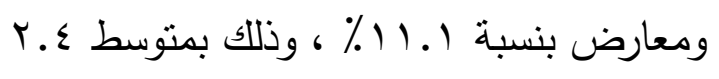

\begin{tabular}{|c|c|c|c|c|c|c|c|c|c|c|}
\hline \multirow{2}{*}{ 裔. } & \multirow{2}{*}{ 亨: } & \multirow{2}{*}{$\begin{array}{c} \\
\frac{7}{3} \\
\frac{3}{3} \\
\end{array}$} & \multirow{2}{*}{ 雹 } & \multicolumn{2}{|c|}{ معارض } & \multicolumn{2}{|c|}{ محايد } & \multicolumn{2}{|c|}{ موافق } & \\
\hline & & & & $\%$ & ك & $\%$ & s & $\%$ & s & 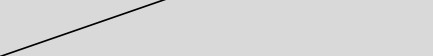 \\
\hline & $r$ & $\begin{array}{l}i . \\
r\end{array}$ & ir & $V_{Y . \Lambda}$ & 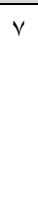 & 11.1 & 1 & 11.1 & 1 & 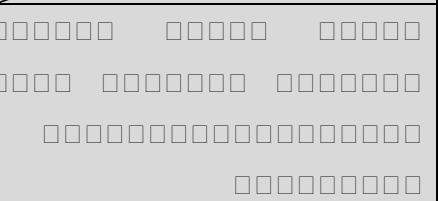 \\
\hline & $r$ & $\begin{array}{l}r . \\
r\end{array}$ & $r$ & 11.1 & 1 & $\varepsilon \varepsilon . \varepsilon$ & $\bar{s}$ & $\varepsilon \varepsilon . \xi$ & $\xi$ & 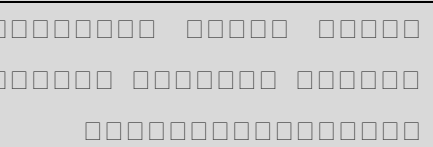 \\
\hline & $r$ & $\begin{array}{l}r . \\
r\end{array}$ & $r$ & & . & T1.. & 1 & rr.r & $r$ & 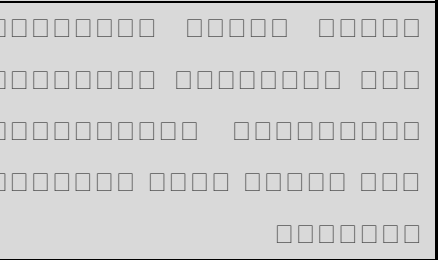 \\
\hline
\end{tabular}

جدول رقم (1)

طبيعة دور ممارسي العلاقات العامة بدقة 


\begin{tabular}{|c|c|c|c|c|c|c|c|c|c|c|}
\hline \multirow{2}{*}{ 商. } & \multirow{2}{*}{ 高 } & \multirow{2}{*}{$\begin{array}{l}\overline{3} \\
\overline{3} \\
\frac{7}{7} \\
\overline{7} \\
3 \\
3\end{array}$} & \multirow{2}{*}{ 言 } & \multicolumn{2}{|c|}{ معارض } & \multicolumn{2}{|c|}{ محايد } & \multicolumn{2}{|c|}{ موافق } & \\
\hline & & & & $\%$ & ك & $\%$ & ك & $\%$ & ك & 7 \\
\hline & 1 & $\begin{array}{l}\text { r. } \\
\text { v }\end{array}$ & $r \varepsilon$ & . & · & Tr.r & $r$ & T.V. & 7 & 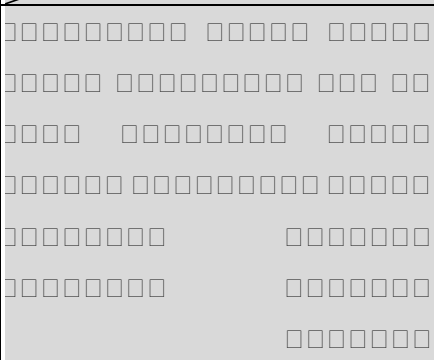 \\
\hline
\end{tabular}

يوضح الجدول السابق طبيعة دور ممارسي العلاقات العامة بدقة وذللك على النحو : التالى

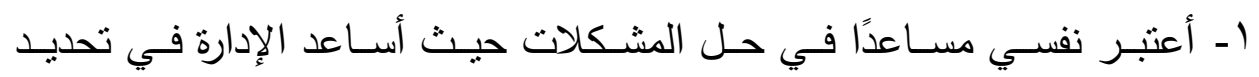
المشكلات ووضـع الأهـداف وتخطيط البـرامج بطريقـة منتظمـة : حيـث كـان

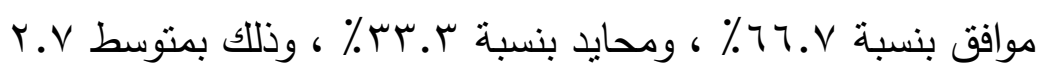

r- اعتبر نفسي المختص بكتابـة وإنتاج مواد العلاقات العامـة : حيث كان موافق

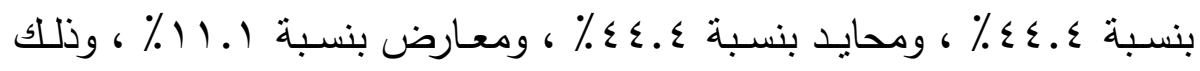

$$
\text { بمتوسط r. }
$$

بـ أعتبر نفسي الوسيط بين الإدارة العليا والجماهير المختلفة حيث أعمل على

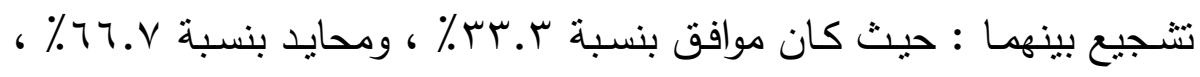

$$
\text { وذللك بمتوسط r.r }
$$


عـ أعتبر نفسي ممثل الجامعة الوحيد في تتخيص وحل المشكلات الجامعية :

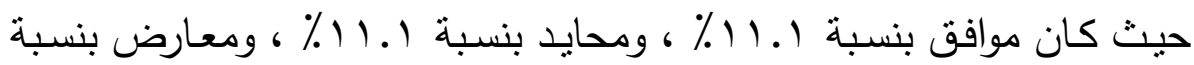

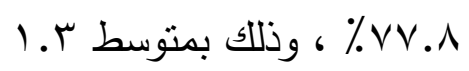

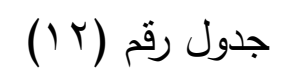

مشاركة افراد العينة في الاجتماعات التي تعقدها الإدارة العليا فيما يتعلق

بالموضوعات

\begin{tabular}{|c|c|c|c|c|c|c|c|c|c|c|}
\hline \multirow{2}{*}{ 高 } & \multirow{2}{*}{ 高! } & \multirow{2}{*}{$\begin{array}{c}\overline{3} \\
\overline{3} \\
\overline{3} \\
\overline{7} \\
3 \\
3 \\
\end{array}$} & \multirow{2}{*}{ 司 } & \multicolumn{2}{|c|}{ معارض } & \multicolumn{2}{|c|}{ محايد } & \multicolumn{2}{|c|}{ موافق } & \multirow[b]{3}{*}{ 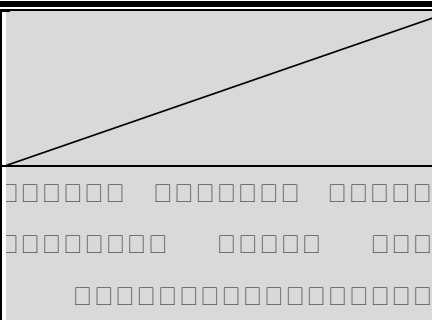 } \\
\hline & & & & $\%$ & ك5 & $\%$ & ك) & $\%$ & ك & \\
\hline & $r$ & $\begin{array}{l}r . \\
r\end{array}$ & $r \varepsilon$ & $\cdot$ & . & rr.r. & $r$ & Tr.V & 7 & \\
\hline & 1 & $\begin{array}{l}r . \\
\wedge\end{array}$ & ro &. & . & TY.Y & $r$ & $V V . \Lambda$ & V & 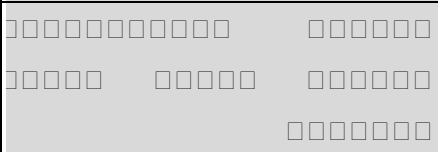 \\
\hline & $r$ & $\begin{array}{l}r . \\
\text { r. }\end{array}$ & $r \leq$ & . & . & r.r. & $r$ & Tצ.V & 7 & 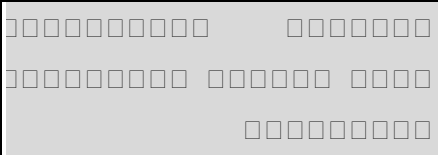 \\
\hline & $r$ & $\begin{array}{l}\text { r. } \\
\text { v }\end{array}$ & $r \varepsilon$ & . & . & r.ז & $r$ & T4.V & 7 & 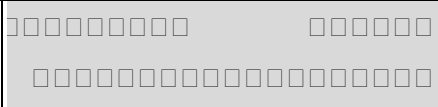 \\
\hline & $\varepsilon$ & $\begin{array}{l}\text { r. } \\
\text { r. }\end{array}$ & $r r$ &. & . & $\varepsilon \varepsilon . \varepsilon$ & $\varepsilon$ & 00.1 & 0 & 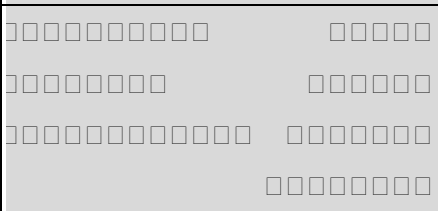 \\
\hline & $r$ & $\begin{array}{l}\text { r. } \\
\text { v }\end{array}$ & $r \varepsilon$ & . & . & r.ז. & $r$ & T4.V & 7 & 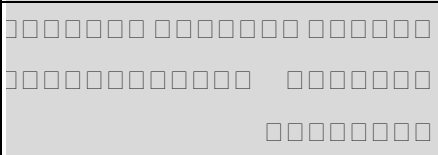 \\
\hline
\end{tabular}


يوضـح الجدول السابق مشاركة افراد العينة في الاجتماعات التي تعقدها الإدارة العليا فيما يتعلق بالموضوعات وذللك على النحو التالى :

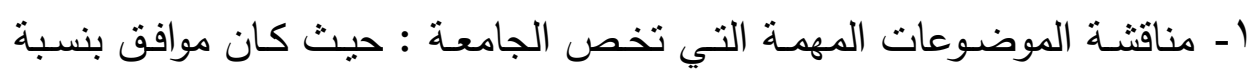

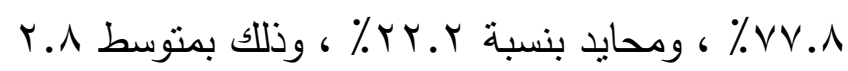
r- اتخاذ قرارات تهدف إلى تبني سياسات جديدة في الجامعة : حيث كان موافق

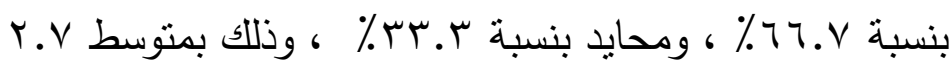
r- استعراض المشكلات التي تواجه الجامعة وسبل حلها : حيث كان موافق بنسبة

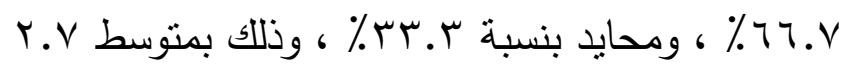

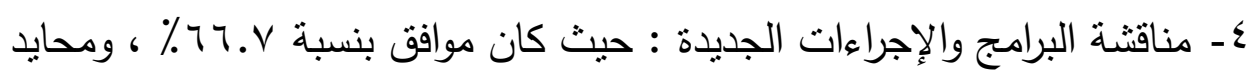

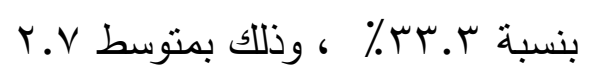

○ـ مناقتشـة وتقويم نتائج البرامج والإجراءات الجديدة : حيث كان موافق بنسبة

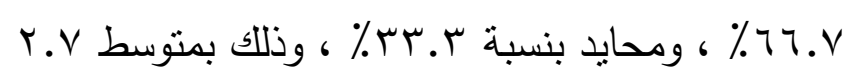

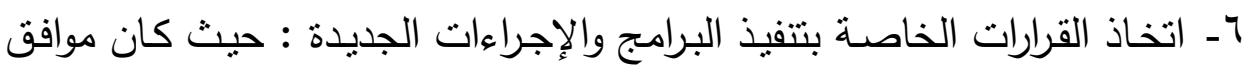

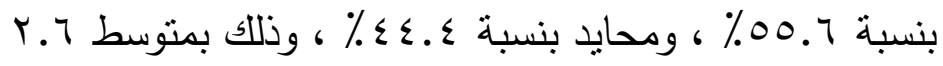




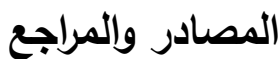

ا. تيسير بن موسي ، المجتمع الليبي في العهد العثماني ،(بنغازي: دار الكتب

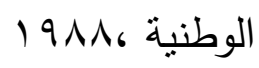

r. جيهـان رشتـي ، الأسس العلميـة لنظريـات الإعـام ، ( القـاهرة: دار الفكر

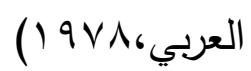

r. حجاج غانم ، الإحصاء التربوي يدوياً وباستخدام SPSS ، (القاهرة : عالم

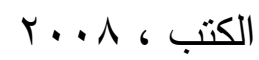

؛. سهير بدر ، البحث العلمي،( القاهرة: دار المعارف ،9199)

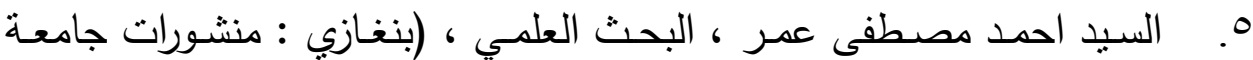

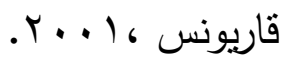

7. صلاح الدين جوهر ، علم الاتصال ومفاهيمه ، نظرياته ، مجالاته ،(القاهرة:

مكتبة عين شمس، • 191

V. عبد الناصر احمد جرادات ، لبنـان هاتف الثـامي ، أسس العلاقات العامة بين النظرية والنطبيق، (عمان: دار اليازوري العلمية للنشر والتوزيع.

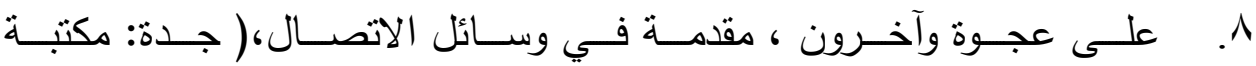

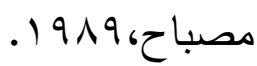

9. علي مصطفي المصراتي ، صحافة ليبيا في نصف قرن ،(بيروت : دار

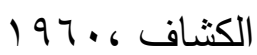

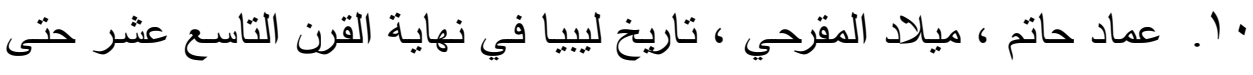

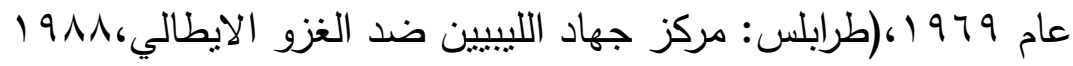

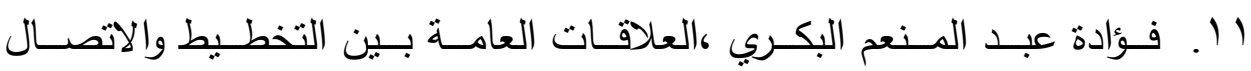

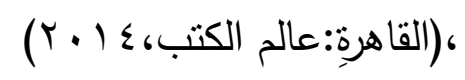


r ب. فؤاده البكري ، الاتصال الثخصي في عصر تكنولوجيا الاتصالات ،(القاهرة:

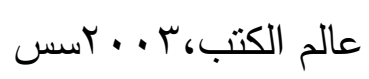

rا.. محمد السيد فهمي ، تكنولوجيا الاتصال في الخدمة الاجتماعية ،(القاهرة: دار

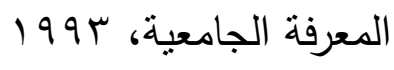

§ ا. . محمد حمد عروس ، الأسس الفنية للإذاعتين المسموعة والمرئية ،( بنغازي:

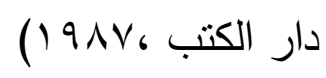

10. محمد ناجي جوهر ، أجهزة العلاقات العامة في العراق ،(بغداد: دار الرشيد

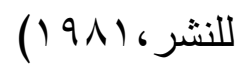

